\title{
Principals' Self-Efficacy Beliefs about Managing Bullying Cases in Secondary Schools
}

\author{
* Malahat Fuad Siddiqui, MPhil Scholar \\ ** Dr. Yaar Muhammad, Assistant Professor (Corresponding Author) \\ *** Hadiya Naseer, MPhil Scholar
}

\begin{abstract}
School education is termed as the foundation that has the whole life of the child dependent upon. Schools are expected to be at par with the latest educational trends, shaping the students' personalities by mitigating the adversities of life yet contemplating skills needed to succeed in life later on. For the very same reason, modern schools ensure an overall environment conducive to the overall development of children. Several factors can hinder the process, among which bullying in schools has become the major concern. School principals have the encumbrance to maintain a hassle-free environment and an uninterrupted teaching-learning process in school. The study, therefore, sought to explore the efficacy beliefs of the principal to deal effectively with bullies while interplaying with different paradigms of bullying management. The theoretical framework was nested in the six approaches presented by Rigby as in Traditional Disciplinary Approach, Strengthening the Victim, Mediation, Restorative Justice, The Support Group Method, and the Shared Concern Approach. A Phenomenological research design was used, and seven principals of schools in Lahore were selected as participants of the study through purposive sampling. A self-constructed, semistructured interview guide was used as the basic data collection tool. The obtained data were interpreted to meaningful information in relevance to the study by using profiling and then the reflexive thematic analysis technique. Findings revealed that participants are well aware of the concept of bullying, its types, and the adversities associated with bullying. Most of them have devised their hybrid systems to counter bullying in their schools. However, strengthening the victim was found to be the approach the participants feel most efficacious to work with. They regard it fruitful and rewarding in terms of the outcome.
\end{abstract}

Keywords: Bullying in School, Bullying Management Approaches, Interviews

\section{Introduction}

Schools are responsible for establishing learning environments and are also crucial for shaping the personalities of their students. Therefore, modern schools are more focused on providing environments conducive to the overall development of children by addressing their mental, physical, and social needs. Several factors can hinder the process posing serious consequences to last for an individual's life-time. Among such factors, "Bullying" has emerged as a widely researched topic (Farrington, 1993; Rigby, 1997; Koo, 2007; Thomas, Connor, \& Scott, 2017; Rigby, 2020a). Most researchers describe bullying as the repetitive negative intentions of one or more persons to inflict psychological or physical harm to a person or more. It usually occurs concerning the imbalance of power or strength (Farrington, 1993; Rigby, 2010, 2020a).

Bullying is considered the most dreadful issue among all age groups in schools (Rigby, 1997). Bullying has adverse effects on school-going children, and it has become a significant health concern for children within this age group (Rigby, 1997). A systematic review reported the prevalence of bullying to be $35 \%$ and $36 \%$ of the victimizing in students belonging to $12-18$ years (Modecki, Minchin, Harbaugh, Guerra, \& Runions, 2014). Some studies showed a relatively lower prevalence in Norway and other Scandinavian countries (Kvarme, Haraldstad, Helseth, Sorum, \& Natvig, 2009). Bullying prevalence in Gujrat, Pakistan, is found to be higher than in earlier discussed countries. A

* Department of Education, University of Management and Technology, Lahore Email: f2018262013@umt.edu.pk

** Department of Education, University of Management and Technology, Lahore Email: Yaar.Muhammad@umt.edu.pk

*** Department of Education, University of Management and Technology, Lahore Email: hadiyanaseer3494@gmail.com 
study stated that $50.5 \%$ of the students engage in bullying, whereas $42.6 \%$ constitute the victims (Shehzadi, Akram, Dawood, \& Bushra Bibi, 2019).

Bullying is often regarded as a subset of aggression that has severe short and long-term psychological and socio-emotional aftermaths. Children who are bullied in schools have developed severe health-related issues, including depression, social anxiety, low self-esteem, injured selfconcept, poor cognitive skills, and lower academic performances later in life (Rigby, 1997). Yet, the students who engage in the act of bullying are equally vulnerable to severe health-related issues and are often reported to have developed antisocial behaviors, depression, post-traumatic stress disorders (PTSD), and feelings of extreme guilt and shame. If health issues related to bullying are left unaddressed, it may lead to the pervasiveness of suicidal ideation among the victims and the bullies (Rigby, 1997; Axford et al., 2020).

Though bullying is linked to several internalizing and externalizing factors, studies have shown a strong tendency of engaging in bullying among students with passive family backgrounds, aggressive households, association with any hostile member of the family, authoritative or cold parenting, and socially prejudiced parents (Rigby, 2010). Besides, any child who wishes to enjoy social dominance drives satisfaction from inflicting pain, has little empathy for others, aspired or encouraged by peer groups, and may opt to adopt bullying to satisfy his needs. Bullies often accused the victims of provoking them as an excuse for bullying them (Rigby, 1997). Bullies are often obstinate to school rules, apt at breaking them, and possess a rebellious attitude (Batsche \& Knoff, 1994). On the other hand, victims are often perceived as whim, weak, nerd, and frightened (Rigby, 2010).

Among the four major forms of bullying, direct bullying is developed among preschool students, takes its peak during primary school years, and declines in secondary school years. While physical bullying has declined gradually, verbal bullying is constant throughout the school years and is the most commonly used form of bullying in schools (D Olweus \& Gredler, 1993). However, unfair social exclusion and cyberbullying are more common among senior school year students (Rigby, 2010). School size and setting (rural, urban) and ethnic composition are said to have been strong factors for the occurrence of bullying in schools (Larochette, Murphy, \& Craig, 2010; Fink, Patalay, Sharpe, \& Wolpert, 2018).

Because bullying is complex, it is necessary to understand the big picture of those directly or indirectly having roles to play in bullying. Though bullies and victims are directly involved in bullying, bystanders have their significance. Most of the bystanders abominate bullying, but they choose to remain neutral for fear of being pointed out as the next target. Also, bystanders may influence the bullies and encourage them to bully others (Rigby, 2010, 2020a). However, some feel sorry for the victim and try to ease the situation in their capacity (Rigby, 1997). Studies have also shown that victims seldom seek help from their teachers or parents; they think intervention from teachers or parents is ineffective and only brings in more harassment from the bullies (D Olweus \& Gredler, 1993; Rigby, 2020b).

\section{Literature Review}

School management is responsible for promptly addressing any reported bullying cases within their schools and should have defined policies and procedures compliant with the school's culture. Therefore, school principals are required to have cognizance of bullying behaviors and bullies. Thus, the principal's ability to intervene in the cases can be phenomenal in preventing bullying in schools.

The concept of self-efficacy is important in this regard. In social cognitive theory, Bandura describes self-efficacy as an individual's beliefs in his capacities to execute such behaviors necessary to yield specific results (Bandura, 1977, 1986). It also considers the ways a person thinks of his successes, failures, and perception of the feedback they receive (Bandura, 1994). Thus, self-efficacy beliefs are responsible for the behavior change (Natvig, Albrektsen, \& Qvarnstrom, 2003). Also, the higher the self-efficacy beliefs, the higher the self-belief will be (Bandura, 1994).

Four main sources of influence develop the concept of self-efficacy. Mastery Experiences:

Individuals, when facing a challenging situation, rely on their ability to overcome obstacles through persistent efforts. Vicarious Experiences: The way individuals observe the social models similar to themselves and their performance facilitates a positive change necessary to execute the required behavior. Verbal Persuasion: Receiving compliments tends to lessen the tendency of harboring self-doubts, thus strengthening the confidence in abilities yielding required results. 
Physiological Arousal: It deals with the physical or mental ability of an individual to deal with complex situations. Anxiety and depression have a negative correlation with self-efficacy.

All these four influencers of self-efficacy do not operate in isolation to either of the concepts; rather, they operate together to influence self-efficacy. While addressing the bullying cases being reported, a principal has to make many decisions. The first and foremost decision taken is of intervening. The decision of when to intervene and how to intervene set the direction for the prevalence of bullying in school and vice versa. The success of policies, procedures, and protocols to intervene depends on their implementation, and the implementation is subjected to the principals' self-efficacy beliefs. Henceforth, the relationship between the self-efficacy of the principals and the intervention method is evident. Effective intervention requires past experiences and lessons learned from them to get the desired action. This action will not yield fruitful results if the principal is not efficacious enough. Therefore, a high level of self-efficacy works as a catalyst in shaping prompt response (Bandura, 1994).

Pakistan, as a developing country, is still struggling in many areas of education. Schools in Pakistan differ not only on a social-class basis but also on the curriculum they taught, the medium of instruction, and their services. Henceforth, a different environment has its role in establishing a bullying-free climate or vice versa. Research studies show that principals of private schools in Pakistan lack adequate professional competencies to manage the schools (Hartijasti \& Afzal, 2017), let alone bullying.

Research studies show that principals' self-efficacy beliefs are important in shaping the school's overall environment (Goddard \& Salloum, 2011). It helps teachers in improving their own self-efficacy beliefs (Versland \& Erickson, 2017). The principal's self-efficacy greatly influences his decision-making process and the implementation of the strategies. The implementations are vital in creating a collaborative environment, which boosts teachers' self-efficacy while performing the desired procedure, thus enabling an operationalized sense of vision and mission (Versland \& Erickson, 2017) and developing and strengthening an overall culture of improvement within schools.

The literature on bullying has been growing since 1990. The social stigmas attached to bullying are no more anecdotal. An evident body of research elaborates the adverse consequences of bullying not for the people involved in bullying but also for society. Because bullying victimization has become a serious concern across the globe and a substantial body of research has linked bullying to detrimental repercussions not only for victims but the perpetrator and the bystanders as well (D Olweus \& Gredler, 1993; Crick \& Grotpeter, 1995; Dan Olweus, 1996; Foltz-Gray, 1996; Rigby, 1997; Craig \& Pepler, 2003; Rodkin \& Berger, 2008; Rigby, 2010; Hepburn, Azrael, Molnar, \& Miller, 2012; Baier, Hong, Kliem, \& Bergmann, 2019). Surveys conducted by WHO reveal the prevalence of bullying in as many as 41 countries worldwide. These surveys reported that reduce was observed in bullying during 2002-2010. Contrary to these reports, research studies show that bullying remained a problem within the given time bracket. Moreover, studies also revealed a hike in bullying culture despite the availability of numerous bullying management strategies and programs (Kousholt $\&$ Fisker, 2015).

Several evaluation studies on bullying management programs reveal that such programs are somewhat inconsistent in their outcomes. They either show no progress at all or show little progress in reducing bullying (Smith, Schneider, Smith, \& Ananiadou, 2004; Baldry \& Farrington, 2007; Ferguson, Miguel, Kilburn Jr, \& Sanchez, 2007; Vreeman \& Carroll, 2007; Rigby \& Slee, 2008). On the contrary to these findings, a study gives hope by declaring that anti-bullying programs, in general, were successful in reducing victimization by $20 \%$ in schools (Baldry \& Farrington, 2007). Also, a study stressed that bombarding schools with anti-bullying programs and management strategies would make no difference until bullying and its various components are entirely understood by school management and teachers (Walton, 2011). It is essential to understand the complex nature of bullying and the nuanced roles of bullies; for instance, bully-victims are the students who bully and are also victimized (Vreeman \& Carroll, 2007). The multiple positions of bullies lay a greater emphasis on the inclusion of social context as the basis of bullying (Kousholt \& Fisker, 2015).

There is a growing research body focused on studying bullying, its causes, participants, and its consequences in Pakistani schools (Shujja, Atta, \& Shujjat, 2014; Branson, Baig, \& Begum, 2015; Hartijasti \& Afzal, 2017; Shamsi, Andrades, \& Ashraf, 2019). However, there seems to be a gap in the management of bullying in schools in Pakistan. The studies show that principals' self-efficacy 
beliefs are crucial for the success of several school procedures (Goddard \& Salloum, 2011; Branson et al., 2015; Versland \& Erickson, 2017). Therefore, the research conducted for this paper attempts to investigate the school principal's self-efficacy beliefs regarding bullying management using the lens of Ken Rigby's Bullying Intervention in Schools. This study is also meant to add to the existing knowledge of bullying and its management in Pakistan's schools. It will help policymakers develop policies preventing bullying in schools to respond to bullying effectively and efficiently.

\section{Theoretical framework}

The timely intervention is by and large crucial for schools; however, the argument continues-what constitutes as key ingredients of best intervention policies? A conceptual framework was developed based on Ken Rigby's six basic approaches to intervene in bullying in schools. He tagged the basic six approaches as "disciplinary approach," "strengthening victim," "mediation," "restorative practice," "The support group Method," and "The Method of Shared Concern." He explains that while deciding on the methods, the principal should consider the assumptions they make and their possible consequences (Rigby, 2010).

He regarded the Traditional Disciplinary approach as the most widely used approach across the globe. It focuses on seeking justice for the victim by inculcating negative consequences to the bully and may also help refrain potential bullies from being engaged in bullying others. Though it is the most widely used approach, it is successful while dealing with younger students. Since the approach focuses on the inappositeness of behavior rather than the unworthiness of the bully, it encourages the use of positive reinforcements to strengthen the desired behavior whenever required (Rigby \& Slee, 2008).

Strengthening the victim works with improving the victim's self-esteem by teaching him social skills and bears very fruitful results if successful. However, the approach's success depends on the victim's ability to acquire new skills. Also, this approach can only address a little imbalance of power between bully and bullying and becomes ineffective if the bully is more physical to the victim(Rigby \& Slee, 2008; Rigby, 2010).

Mediation involves settling the differences between the bully and his victim with the help of a trained mediator. A mediator may be a teacher or a student. It is less likely to be used successfully in schools as it requires the willingness of both the bully and the victim to work towards a mutually acceptable solution. Sometimes the mediator finds it challenging to remain neutral towards the imbalance of power (Rigby \& Slee, 2008).

Restorative justice believes in reinstating the bully and his victim's positive relations if the bully feels remorse for his wrongdoings. This approach is less likely to be successful in cases where victims have pre-requisites of an unforgiving mindset. In severe bullying cases, community conferences work as an alternative to legal actions to harmonize the differences by establishing an environment of mutual concern (Rigby \& Slee, 2008).

The Support Group Method avoids blaming the bully for his wrongdoings rather enables the bully to respond emphatically to the harm his actions have brought to the victim. The approach has its limitations as it requires the bully's empathetic concern and availability of peers who can willingly work with practitioners to support the victim and henceforth can't address cases with extreme violence (Rigby, 2010).

The Method of Shared Concern works on the assumption that the act of bullying is commonly undertaken by or with the support of a peer group. The approach is also non-accusatory in nature and works on resolving the conflict by holding several meetings with the identified bully or with those who have been providing support to the bully as an individual and then by holding a group meeting. The core purpose is to attain an agreed resolution; however, the approach is not very successful for primary and younger students. Schools sometimes may choose to apply a hybrid version of the approach, blended with the Support Group Method. The approach may require outsourcing a trained specialist and time and resources; hence is least likely to be used by the school management (Rigby \& Slee, 2008; Rigby, 2010).

\section{Purpose of the Study}

This study aims to analyze the self-efficacy beliefs of principals about the management of bullying in schools. 


\section{Methods}

A phenomenological approach allowed the researchers to delve into the school context to understand and describe the principal's bullying management practices. The design suits the study best because it allowed the principals to tell their stories, share their understandings of bullying, and quote their reallife experiences to help the researcher understand their self-efficacy level concerning bullying management in their schools. The unit of analysis for this study is "principal's self-efficacy beliefs," and the concern is "bullying management using the lens of Rigby's six approaches."

\section{Research Sites and Participants}

For the collection of data, schools located in Lahore were selected. The responses were taken in oneon-one interviews with the participants of the study. The participants were the principals of the schools. The data collected were based on their responses about how efficacious they feel about managing bullying cases in their school.

The selection of participants was purposefully made while having the theoretical framework and research purpose as the guiding principles. While making the selection for the participants and schools, it was ensured that the principal had experienced bullying in his or her school and is the core authority for managing bullying cases in the school since the current research study aims to study principals' understandings about bullying and their approaches to managing bullying cases.

Prior consent of the principals was taken on call. Principals and their staff were friendly, cooperative, and supportive. Principals were open and expressive and have spoken their hearts out. In some cases, principals were eager to share their life experiences to such an extent that they exceeded the time booked with them.

\section{Participant inclusion criteria}

Following criteria were used to decide the inclusion of participants in this study: The participant had at least three years of working experience as a principal in a secondary school with a prevailing environment of bullying in his/her school—having a fee structure under 5000 PKR per month.

Table 1: Demographic information of the participants.

\begin{tabular}{clllll}
\hline Participant & Gender & Age & Academic Qualification & $\begin{array}{l}\text { Experience } \\
\text { (Years) }\end{array}$ & School \\
\hline 1 & Female & 43 & MPhil ELM & 10 & Private \\
2 & Female & 52 & MA History. & 18 & Private \\
3 & Male & 39 & MSc IT & 3 & Private \\
4 & Female & 41 & MBA & 10 & Private \\
5 & Male & 41 & BSc & 5 & Private \\
6 & Male & 59 & MA Political Science & 30 & Private \& Public \\
7 & Female & 39 & BBA, MA Economics & 5 & Private \\
\hline
\end{tabular}

\section{Data Collection Methods}

Semi-structured interviews were conducted to collect data for this study from 7 private school principals of Lahore. It is the most common type of interview used in qualitative research. The researcher tends to ask the same questions to every participant of the study to get specific information. The information gained from interviews is then compared and contrasted with extracting commonalities and differences from participants' points of view (Patton, 2004). The use of semistructured interviews for the current study allowed the researchers to ask open-ended questions to develop a deeper insight into how their self-efficacy has been shaped and to get a nuanced understanding of their bullying management experiences in their schools.

\section{Interview Guide}

This study used a semi-structured open-ended interview format to collect data from the selected participants. A review of the literature identified the areas on which the guide has been developed. The interview guide was comprised of seven inquiry areas. The first area collected the demographic information of the participant. The rest of the six areas tended to explore the principal's understanding of six bullying management approaches. The interview guide was comprised of 30 questions. Initial questions were based on the general understanding of bullying to build a rapport with the interviewee.

The initial draft of the interview guide was discussed in a meeting of all researchers, and after discussion, the interview guide's questions were finalized. However, some alterations were made based on the feedback received in the meeting resulting in the addition of questions meant to gauge the more in-depth understanding of the phenomenon of bullying in section A, whereas some questions used jargon so much so that it became difficult to understand for a common person. In addition, 
amendments were made to enhance clarity. The order of the questions also needed cohesion, so they were rearranged to a more logical and meaningful sequence.

The interview guide was further improved by piloting it with a principal, playing a critical friend's role. The piloting highlighted the difference in the context the questions were asked and the perception of the participants. Henceforth, the interview guide was revised. Some questions were removed some new questions were added. Also, the language of the questions was amended to ensure the clarity and context of the participants.

\section{Interview Process}

The first researcher conducted all the interviews. Having associated with the same profession as of the participants, contacting the eligible participants was not as daunting of activity for the researcher as it is for most researchers. The researcher used her personal and professional resources to locate schoolbased principals. However, to ensure the study's trustworthiness, the researcher avoided selecting participants from her immediate circle of colleagues and friends. Principals' consent and willingness to participate were initially asked on the phone. 10 principals were contacted; two did not meet the criteria necessary to participate in the study, and one refused to participate in the study. Seven principals were interviewed.

Interviews were kept open-ended, semi-structured to avoid the variation in questions posed to the interviewees (Patton, 2004). All the participants were interviewed at decided locations at the time that was convenient for them. Interview format and procedures were explained to each participant. English was used as the primary medium; however, participants were encouraged to answer in Urdu if they so wish and hence interviews, most of the time were conducted both in Urdu and in English. Casual questions about their daily routine and the challenges they faced every day as a school head were asked in the beginning to build a rapport with them. Hence, the honest flow of information was ensured. Two participants demanded to see the guide prior to the interview. A topic guide was provided to both of them.

Interviews were recorded using two android phones and with the consent of the participants. The researcher paid heed to the body language and facial expressions to decode the informal cues. The researcher also took notes of the points wherever it felt necessary. The interviewees were asked probing and follow-up questions when needed. The interviews lasted for a minimum of 45 minutes and a maximum of 3 hours of duration.

All interview recordings were transcribed verbatim and translated in the English language, typed, and saved both in hard and soft form for later use. Follow-up interviews were conducted to ensure the honesty and trustworthiness of the studies. Member-checking by letting the participants review and make changes in the transcripts used for drawing themes was also performed to ensure the data's accuracy (Yin, 2018; Candela, 2019). Furthermore, to avoid data obscurity, the first researcher kept a journal to record her personal biases.

\section{Data Analysis Methods}

The method applied to analyze the interview transcripts was the reflective thematic analysis (Braun, Clarke, Hayfield, \& Terry, 2019; Braun \& Clarke, 2020). Reflexive thematic analysis can be approached inductively as well as deductively. Since the study sought to analyze school principals' self-efficacy about bullying management in schools using the lens of Rigby's six approaches of bullying management, this study adopted the deductive approach. A deductive way of coding and theme development is driven by the existing concepts and ideas.

It is recommended that reflexive thematic analysis is to be conducted in six phases. These phases facilitate the within back-and-forth movement for rigorous data engagement. First, familiarization with the data entails that the researcher read the available data, again and again, to become immersed and develop a familiarity with the available data set. For the current study, the researcher listened to each interview several times and compared and contrasted the recorded interviews with the transcripts. This allowed the researcher to indulge in the data set and identify the major findings later during the analysis. Second, key issues and concepts were identified while familiarizing with the data and were labeled in the coding phase. Third, initial themes were generated, grouping the obtained information under the broader themes and rearranging their relevant themes. Fourth, the grouped information was analyzed to extract meanings in context to the generated themes for reviewing themes. Fifth, defining and naming themes phase helped in processing the data into meaningful information by comparing and contrasting. Sixth, the final stage helped in the weaving of 
the information so that it makes sense for the reader and presents the findings in a way that supports the rationale of the study agenda.

\section{Findings}

\section{Managing bullying through the disciplinary approach}

The traditional disciplinary approach focuses on rectifying the behaviors of the offender. The system is usually based on clearly defined rules and regulations to be followed by the students to ensure smooth school proceedings and a safe environment. In case of disruption, the system strictly deals with the offender depending upon the severity of the offense caused. The same goes for the bullies. After having developed a global disliking for the practices that believe in inflicting pain to the students either, mental, physical, or emotional, schools in Pakistan are less likely to use the strategy. The findings of the current study also supported that though it is not practiced in schools anymore, yet the principals perceived it as the most effective of all the approaches to manage bullying in schools.

It is visible and measurable. The disciplinary approach certainly has its impact on the students on the whole and not only on the recipient. Also, families take it more seriously as compared to any other approach. (Participant 5)

All seven participants of the study felt efficacious while implementing the approach, yet, owing to the adverse effects of the approach, they were less likely to implement the approach in their campuses. Three participants used the disciplinary approach in their schools, and they had a defined system of penalties and sanctions such as time out of the class, ban on curricular and co-curricular activities, slapping, making students stand in class or outside the class as punishments, and rusticating students in extreme cases. Three participants disliked the strategy for the harm it brings to the students. For example, a participant stated,

My teachers and I are strong believers that punishment shatters a student's confidence and urges him to become stubborn and rebellious, thus risking the overall well-being of the child. (Participant 3)

Four participants have strictly banned the use of all types of punishments to be used in schools. Participants also expressed that the approach is very stereotypical in its implementations, that it succors the victim and deprives the bully of his right of being a child and commit mistakes. "In the wake of mending one (victim), we wreck the other (bully). We ought to realize that how brutal a bully may become; he is still a child who needs an equal amount of sympathy (Participant 6).

\section{Managing bullying through the strengthening the victim approach}

All the participants of the study defined it as an essential part of their bullying management system; however, the ways of implementation differed from each other. The participants believed that schools should nurture a culture embedded in which activities enable a child to raise a voice whenever he feels offended. Having said that, it is also equally important to understand the strengthening the victim operates on two principles only: Being defensive in a way that does not hurt the bully and avoid being identified with the mind.

The skills that participants identified necessary to strengthen a victim were building students' self-confidence and self-esteem, enabling them to approach elderly help when they feel offended, quick-wittedness, and spontaneity. Participants reported that handling verbal bullies was comparatively easier as the victim could be easily trained either not to respond at all and let the bully babble on its own or to cut the cackle and just leave the bully dumbstruck by engaging him in counterarguments. However, none of them believed that enabling a victim to respond to a physical bully is recommended in any situation. For example, a participant stated,

If I tell the victim to go physical, the chances are high that in frustration, he will react with double intensity causing severe injuries. Also, it can never be ensured that the skills will only be used as a self-defense tool, and the victim will not transform into the bully himself. (Participant 3 )

Activities such as debates and performing the rituals at morning assembly, joining the school drama club, moral lectures, and sessions with the principals help boost the confidence of the victim. Participants were practicing the approach with confidence and were very much satisfied with the outcomes; however, one of the participants reported to have been using a hybrid version of discipline and strengthening the victim. Rather than focusing on the victim or the bully, he worked on both and provided counseling to both of his students in parallel sessions. He asserted, 
No intervention strategy can ever be successful that addresses either the bully or the victim. They both are suffering. They both need help. Strengthening the victim brings profuse results when accompanied by the counseling of the bully. (Participant 3 )

Only one participant has neither practiced the approach in his school nor could he identify the skills that a victim should acquire to face bullying. One of the participants raised a very interesting point. He said having a victim handling a bully on his own, there is a high chance that the issues will not be brought to an elderly notice and thus compromising the health and psychological needs of the victim.

Six out of seven participants believed that the constraints such as unnecessary paperwork that kept the teachers overly engaged and unavailability of resources were undermining the outcomes of the strategy.

\section{Managing bullying through the mediation approach}

Participants defined mediators as the persons who intervene to settle the issues among the victim and the bully. They believed that a mediator should be empathetic, highly inferable, and highly objective. Above all, a mediator is always a good listener. As a participant reported,

Half of the success is attained when the mediator is trusted as an active listener.

Students will only agree on a suggested solution if they are heard to the level of their satisfaction. (Participant 6)

Though principals believed that a teacher can't remain impartial due to the association, they may have developed with their students, yet they are the first to mediate when an issue of bullying arises. The reason for which they are relied upon as the primary mediators are their availability with the students. However, almost all of the principals had senior levels of the participants who had to onus to ensure the claim's health from both ends. For example, a participant stated,

Students who have a buoyant repertoire and bears a good academic record are generally liberated from any of the accusations. Though they are trained, teachers can't stay neutral towards students they like for long, which is why we have trained our class in-charges to handle and intervene. In our system, you can say a class incharge is the mediator responsible for settling the issue. (Participant 3)

Two participants reported that they had trained their teachers to mediate in the classrooms; however, the results were not much different concerning those not trained. Five participants rejected the probability of training the teachers in this or any issue as they believed that teachers are least interested in investing anything in their professional training. Whereas, teachers' high turnover rate in private schools is yet another barrier in arranging training for the teachers. One participant raised a point that teachers are performing multiple roles in private schools, and it becomes an arduous task for teachers to carry out their duties as the whole system of mediation requires scrupulous feedback and a monitoring system. For example, a participant stated,

Our disciplinary committee is comprised of full-time teachers, including the head of the committee. So, we can't keep written records. We have to rely on discussions and verbal reports, which is a barrier to the transparency of the whole system. (Participant 1)

Only one participant had students working as the initial mediators along with their teachers in the system. Participants, however, believed that students had limited availability and could only resolve the daily routine disruptive cases and not the bullying, to be specific. The rest of the participants rejected the idea of having students worked with their teachers as mediators. All the participants believed that mediation was successful in bullying cases that necessarily do not involve physical bullying. In extreme aggression or violence cases, resolving an issue was not appropriate, and the principal would be expected to carry out the needful procedures concerning school policies.

\section{Managing bullying through the restorative approach}

Restorative relations believe in restoring relations among the bully and victim. Most of the participants claimed that children, regardless of their genders, are usually bound to repent upon their actions if they are made aware of the harms their actions have brought to the victims. One of the participants believed otherwise. She claimed that boys have a revengeful mindset, and to offer them a solution to their satisfaction is yet another strenuous task. 
Victims, boys especially, measure the solution provided in terms of the intensity of punishment. If they think their offender has not to be dealt with enough strictness, they will usually go for revenge. (Participant 2)

Almost all the participants regarded the parents' support as a must-have for the success of the said approach. Restoring relation requires developing a forgiving mindset that can only be done if students are repeatedly engaged in sessions focusing on the virtues of forgiveness and acceptance. Parents' supports are critical in developing such a mindset, and most of the participants claimed to have lacking parents' support in this regard. A participant highlighted,

We need to change the mindsets, not of the bully and his fellows but the bully's parents. Such parents are ignorant at first. Secondly, they usually have overestimated their efficacy in bringing up their kids. They will never accept that their kids can be manipulative or can harm any other. (Participant 4)

All participants believed that they could make students realize that they had been involved in performing incredibly inappropriate actions and thus had to let go of their wrongdoings through counseling sessions while giving them a chance to explain their side of the story. Most participants believed that restoring relations is a continuous process, and students are most likely to resort to their previous state if not monitored closely. Also, they stated that monitoring restored-relations needs rigorous record-keeping of the events, and teachers cannot keep pace with them due to their busy schedules.

\section{Managing bullying through the support group method}

The support group method seeks the support of the students while handling bullying situations. Students are usually bound to develop strong bonds of friendship and are most likely to support their friends in distressing times. The same goes for the bully and his friends. Since there is a famous saying that birds of the feather flock together; therefore, a bully's friends are either bullies themselves or are a supporter of bullying. Participants believed that acquiring help from students was tricky. Yet, most of them stated their students as extremely compassionate, kind, helpful, vocal at times, and supportive for their friends in specific and to their class and school-fellows in general.

Most of the principals regarded ensuring the health of the claims as the first step of the approach. They, however, strongly opposed engaging students while investigating the culprits. Participants regarded management members as solely responsible for upholding the credibility of the claims. While speaking of the procedures, most participants reported they could adapt to deal with situations among the students to engage both the bully and the victim in a dialogue with the concerned personnel. Having identified the bully's supporter, the participants usually held a meeting with the whole class to counsel them in general. The identified victim was then ideally attached to the one willing to help him. Some participants believed that having students being obsessed with the help they get from their friends is the major setback of the strategy.

Some principals believed that this approach was not workable with boys as bully boys are more revengeful and aggressive than girls; therefore, the class, in general, would prefer to stay neutral to avoid being caught in a bully scene.

\section{Managing bullying through a shared concern approach}

This was found to be the least practiced approach. None of the participants believed in bestowing the responsibility on the students for the resolution of the problem. They believed that strategy needs students to respond emphatically to their class fellows in need of help. A few of the participants expressed their confidence in creating such an environment; however, they believed that such a culture could only be promoted in school only with the cooperation of the parents. A few of them regarded teachers as incredulous and oblivious to their duties other than teaching in classrooms. Most of the participants denied having any case of extreme violence having reported in their schools. One of them, however, reported having worked in an organization where sexual bullying was observed. She, in her capacity as the principal, trained her students to shout for help with all their might whenever they felt offended.

\section{Conclusion}

The current study provides insight into the principals' efficacy beliefs while managing the bullying cases in their schools. It was found that principals have a high efficacy while using the strengthening the victim approach; however, they believe in enabling the student to raise a voice against the injustice - and not by handling the bully on its own. Participants also showed great confidence while 
explaining the procedures of the disciplinary approach; however, most of them have abandoned the use of the disciplinary approach in their schools owing to the adverse effects it has on the psychological beings of the students.

\section{The Implication of research}

Since the study is qualitative in nature and selected its participants through purposive sampling, it has certain implications for the institutional leaders and the teachers.

1. The findings of the study are equally important for both while handling the issue of bullying in their schools. This research sought to find the efficacy beliefs of the principals about Rigby's six approaches. Thus, the findings of the study may be helpful for the school leaders in understanding what works best in a different situation and will be able to practice different strategies with confidence.

2. The analysis of the findings makes it clearer that though the principals can successfully detect a bully in their schools and are more inclined to be using the disciplinary approach and strengthening the victim approach for the management of bullying with very high confidence, however, they showed great disbelief in the ability of their teachers to manage bullies in their classrooms.

3. The study suggests that both the teachers and the principals are required to have training on implementation procedures.

4. Also, teacher education curriculum should address bullying management in their contents so that the prospective teachers, school staff, and principals are trained to address the challenges

References (Waasdorp, Fu, Perepezko, \& Bradshaw, 2021).

Axford, N., Bjornstad, G., Clarkson, S., Ukoumunne, O. C., Wrigley, Z., Matthews, J., . . Hutchings, J. (2020). The Effectiveness of the KiVa Bullying Prevention Program in Wales, UK: Results from a Pragmatic Cluster Randomized Controlled Trial. Prevention Science, 21(5), 615-626. Retrieved from https://doi.org/10.1007/s11121-020-01103-9. doi:10.1007/s11121-020-011039

Baier, D., Hong, J. S., Kliem, S., \& Bergmann, M. C. (2019). Consequences of bullying on adolescents' mental health in Germany: Comparing face-to-face bullying and cyberbullying. Journal of Child Family Studies, 28(9), 2347-2357.

Baldry, A. C., \& Farrington, D. P. (2007). Effectiveness of programs to prevent school bullying. Victims and Offenders, 2(2), 183-204.

Bandura, A. (1977). Self-efficacy: toward a unifying theory of behavioral change. Psychological Review, 84(2), 191-215.

Bandura, A. (1986). The explanatory and predictive scope of self-efficacy theory. Journal of social clinical psychology, 4(3), 359-373.

Bandura, A. (1994). Self-efficacy. In. VS Ramachandran. Encyclopedia of human behavior, 4(4), 7181.

Batsche, G. M., \& Knoff, H. M. (1994). Bullies and their victims: Understanding a pervasive problem in the schools. School Psychology Review, 23(2), 165-174.

Branson, C. M., Baig, S., \& Begum, A. (2015). Personal values of principals and their manifestation in student behavior: A district-level study in Pakistan. Educational Management Administration Leadership, 43(1), 107-128.

Braun, V., \& Clarke, V. (2020). One size fits all? What counts as quality practice in (reflexive) thematic analysis? Qualitative research in psychology, 1-25. Retrieved from https://doi.org/ 10.1080/14780887.2020.1769238. doi:10.1080/14780887.2020.1769238

Braun, V., Clarke, V., Hayfield, N., \& Terry, G. (2019). Thematic analysis. In P. Liamputtong (Ed.), Handbook of research methods in health social sciences (pp. 843-860). Singapore: Springer Nature Pte Ltd.

Candela, A. G. (2019). Exploring the function of member checking. The Qualitative Report, 24(3), 619-628.

Craig, W. M., \& Pepler, D. J. (2003). Identifying and targeting risk for involvement in bullying and victimization. The Canadian journal of psychiatry, 48(9), 577-582.

Crick, N., \& Grotpeter, J. K. (1995). Relational aggression, gender, and social-psychological adjustment. Child Development, 66(03), 710-722. 
Farrington, D. (1993). Understanding and preventing bullying. Crime justice, 17, 381-458.

Ferguson, C. J., Miguel, C. S., Kilburn Jr, J. C., \& Sanchez, P. (2007). The effectiveness of schoolbased anti-bullying programs: A meta-analytic review. Criminal Justice Review, 32(4), 401414.

Fink, E., Patalay, P., Sharpe, H., \& Wolpert, M. (2018). Child-and school-level predictors of children's bullying behavior: A multilevel analysis in 648 primary schools. Journal of educational psychology, 110(1), 17-26.

Foltz-Gray, D. (1996). The bully trap: Young tormentors and their victims find ways out of anger and isolation. Teaching Tolerance, 5(2), 18-23.

Goddard, R. D., \& Salloum, S. (2011). Collective efficacy beliefs, organizational excellence, and leadership. Positive organizational scholarship handbook, 642-650.

Hartijasti, Y., \& Afzal, S. (2017). A paradox of school principals' competencies in Pakistan. In Enhancing Business Stability Through Collaboration (pp. 309-314): CRC Press.

Hepburn, L., Azrael, D., Molnar, B., \& Miller, M. (2012). Bullying and suicidal behaviors among urban high school youth. Journal of Adolescent Health, 51(1), 93-95.

Koo, H. (2007). A Time Line of the evolution of School Bullying in differing Social Contexts. Asia Pacific Education Review, 8(1), 107-116.

Kousholt, K., \& Fisker, T. B. (2015). Approaches to reduce bullying in schools - a critical analysis from the viewpoint of first- and second-order perspectives on bullying. Children and Society, 29, 593-603.

Kvarme, L. G., Haraldstad, K., Helseth, S., Sorum, R., \& Natvig, G. K. (2009). Associations between general self-efficacy and health-related quality of life among 12-13-year-old school children: a cross-sectional survey. Health Quality of Life Outcomes, 7(1), 85. doi:https://doi.org/ $10.1186 / 1477-7525-7-85$

Larochette, A.-C., Murphy, A. N., \& Craig, W. M. (2010). Racial bullying and victimization in Canadian school-aged children: Individual and school-level effects. School Psychology International, 31(4), 389-408.

Modecki, K. L., Minchin, J., Harbaugh, A. G., Guerra, N. G., \& Runions, K. C. (2014). Bullying prevalence across contexts: A meta-analysis measuring cyber and traditional bullying. Journal of Adolescent Health, 55(5), 602-611.

Natvig, G. K., Albrektsen, G., \& Qvarnstrom. (2003). Associations between psychosocial factors and happiness among school adolescents. International Journal of Nursing Practice, 9(3), 166175.

Olweus, D. (1996). Bullying at school: Knowledge base and an effective intervention program a. Annals of the New York Academy of Sciences, 794(1), 265-276.

Olweus, D., \& Gredler. (1993). Bullying at school: What we know and what we can do. Psychology in the Schools, 40(6), 699-700.

Patton, M. Q. (2004). Qualitative research and evaluation methods (4th ed.). London: Sage Publication.

Rigby, K. (1997). What children tell us about bullying in schools. Children Australia, 22(2), 28-34.

Rigby, K. (2010). Bullying interventions in schools: Six basic approaches: Aust Council for Ed Research.

Rigby, K. (2020a). How do victims of bullying in Australian schools view their perpetrators - As individuals or as groups? Implications for educators. Australian Journal of Education, 64(1), 25-39. Retrieved from https://journals.sagepub.com/doi/abs/10.1177/0004944119894099. doi:10.1177/0004944119894099

Rigby, K. (2020b). How teachers deal with cases of bullying at school: What victims say. International Journal of Environmental Research and Public Health, 17(7), 2338. Retrieved from https://www.mdpi.com/1660-4601/17/7/2338.

Rigby, K., \& Slee, P. (2008). Interventions to reduce bullying. International journal of adolescent medicine health, 20(2), 165-184.

Rodkin, P. C., \& Berger, C. (2008). Who bullies whom? Social status asymmetries by victim gender. International Journal of Behavioral Development, 32(6), 473-485.

Shamsi, N. I., Andrades, M., \& Ashraf, H. (2019). Bullying in school children: How much do teachers know? Journal of family medicine primary care, 8(7), 2395. 
Shehzadi, N., Akram, B., Dawood, S., \& Bushra Bibi. (2019). Bullying behavior in rural area schools of Gujrat, Pakistan: Prevalence and gender differences. Pakistan Journal of Social and Clinical Psychology, 17(1), 25-30.

Shujja, S., Atta, M., \& Shujjat, J. M. (2014). Prevalence of bullying and victimization among sixth graders with reference to gender, socio-economic status, and type of schools. Journal of Social Sciences, 38(2), 159-165.

Smith, J. D., Schneider, B. H., Smith, P. K., \& Ananiadou, K. (2004). The effectiveness of wholeschool antibullying programs: A synthesis of evaluation research. School psychology review, 33(4), 547-560.

Thomas, H. J., Connor, J. P., \& Scott, J. G. (2017). Long-term effect of bullying. Arch Dis Child, 100(9), 879-885.

Versland, T. M., \& Erickson, J. L. (2017). Leading by example: A case study of the influence of principal self-efficacy on collective efficacy. Cogent Education, 4(1), 1286765. Retrieved from https://www.tandfonline.com/doi/abs/10.1080/2331186X.2017.1286765. doi:10.1080/ 2331186X.2017.1286765

Vreeman, R. C., \& Carroll, A. E. (2007). A systematic review of school-based interventions to prevent bullying. Archives of pediatrics adolescent medicine, 161(1), 78-88.

Waasdorp, T. E., Fu, R., Perepezko, A. L., \& Bradshaw, C. P. (2021). The role of bullying-related policies: Understanding how school staff respond to bullying situations. European Journal of Developmental Psychology, 1-16. Retrieved from https://doi.org/10.1080/17405629.2021. 1889503. doi:10.1080/17405629.2021.1889503

Walton, G. (2011). Spinning our wheels: Reconceptualizing bullying beyond behavior-focused approaches. Discourse: studies in the cultural politics of education, 32(1), 131-144.

Yin, R. K. (2018). Case study research and applications: Design and methods (6th ed.). New York: Sage publications. 